\title{
Paramedics and scope of practice
}

\section{Highly-trained paramedics can initiate the pathway of care that will achieve optimal outcomes for patients}

\begin{abstract}
"The opinion
of patients

is clear:

paramedics

remain one

of the most

trusted

health care

professions"

T he question, posed to me by the Journal's editorial staff, "Are paramedics exceeding the evidence?", is a very global one that implies a dichotomous response. However, nothing in our complex health system can be so simply evaluated, so the question gets an equally global (if vague and unhelpful) answer: "Yes, probably, but no more or less than the rest of health care".

My professional obsession with objective analysis must necessarily be tempered in this instance by my experience in contributing to the professional transformation of the ambulance service, particularly in the 1990s. This transformation resulted in considerable expansion of the scope of practice, underpinned by improved education and training - from in-house unstructured training, through the vocational training sector to university degrees.
\end{abstract}

Gerard J FitzGerald

MD, FACEM, FRACMA

Queensland University of Technology, Brisbane, QLD. gj.fitzgerald@qut.edu.au

doi: 10.5694/mjal5.00775

Podcast with Professor Gerard FitzGerald available at www.mja.com.au/ multimedia/podcasts

The transformation in prehospital care was largely driven, not by evidence, but by the enthusiasm of proponents (mostly doctors) and by emerging international experience. The intellectual foundation was not usually evidence, but rather a defensible and logical rationale. Innovation is often so, because we cannot test system-wide effectiveness without introducing system-wide changes. However, sometimes that rationale is flawed when we make the "conclusional" jump that if anything is worth doing, then doing it earlier will always be better. However the logistical, training, equipment and safety impediments of working in an uncontrolled environment must necessarily influence the clinical cost-benefit analysis.

The problem we confront is both a lack of evidence and the influence of individual, professional, social and economic factors that then influence the scope of clinical practice. These may act contrary to science and its application. Traditionally, paramedics were poorly paid and relied on special allowances and penalty rates to reach incomes that could sustain them. As the scope of practice expanded, the industrial drive was for additional skills to be recognised financially, thus creating an incentive to undertake training and to value competence. There was thus some reluctance in certain quarters to rely on evidence or even a defensible rationale. In 2008, the then Queensland Minister for Emergency Services responded to pressure from staff and ordered the scrapping of a National Health and Medical Research Council-funded randomised controlled trial that aimed to test adrenaline against placebo in managing asystolic cardiac arrest.

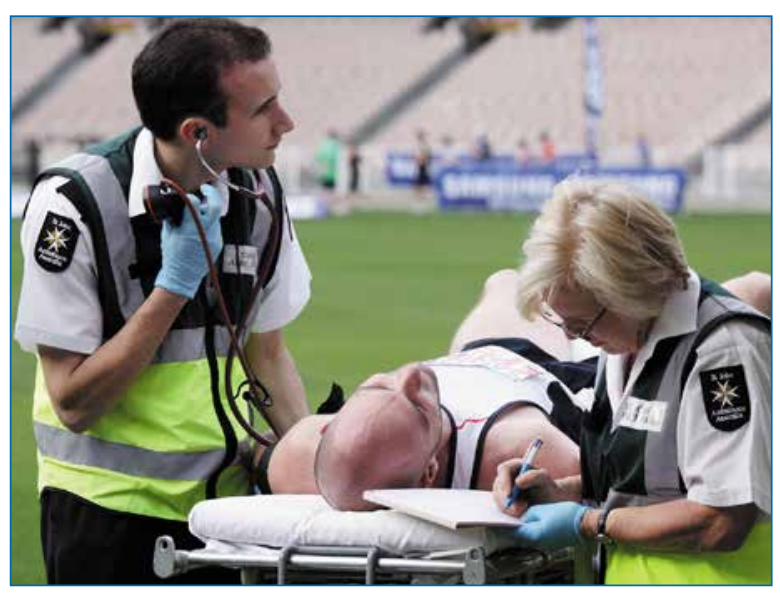

\section{Relating evidence to practice in uncontrolled environments}

Next, while we recognise the capacity of evidence-based care to reduce costs and improve outcomes, ${ }^{1}$ the real challenge is to find evidence that can inform practice. A study in 2007 of almost 20000 candidate articles found only 400 that were relevant to prehospital care, and that there were only 13 reviews. ${ }^{2}$ The Cochrane Library also demonstrates the limited utility of the evidence to inform practice. A review of the use of aminophylline for cardiac arrest found five trials with no survivors. ${ }^{3}$ A report on prehospital thrombolysis showed a reduction in time to thrombolysis, but limited evidence of its safety or on its long-term outcomes. ${ }^{4}$ Finally, a report on the use of oxygen for patients with chronic obstructive pulmonary disease noted that, of 741 abstracts reviewed, only two were of randomised controlled trials, both of which were ongoing and lacking outcome data. ${ }^{5}$ Much of the literature lacks an understanding of how its findings apply in the uncontrolled environment that characterises prehospital care. There are interventions for which the evidence is more clear-cut. Prehospital defibrillation improves survival (patients walk out of hospital).

\section{The real value of highly-skilled paramedics}

I am reminded of the international debate about prehospital management of trauma, which critics reduced to a simplified dichotomy - scoop and run, or stay and play. I wish I could draw, for I would design ambulances as modified garbage trucks or casinos to demonstrate the absurdity of either proposition. Surely what we expect is safe extrication, stabilisation, initiation of care and then securing appropriate ongoing care for the patient. 
It is this last aspect which, to me, represents most value for the massive investments in professional development of paramedics. They are at the sharp end of the patient journey, and best placed to initiate a pathway of care most likely to achieve optimal outcomes. Paramedics' judgement is necessary to bypass to trauma centres, take patients directly to catheter laboratories, or reduce the burden on emergency departments by treating patients in situ or directing them to more appropriate and cost-effective care options. ${ }^{6}$

For relatively smart people, we seem to struggle with complexity, and we try to reduce complex issues into binary thinking - on or off. The reality is always more complicated. The opinion of patients is clear: paramedics remain one of the most trusted health care professions. However, to retain that trust there is a professional imperative for research into prehospital care to seek the evidence or, at least, a defensible rationale so that the patient's best interest retains its primacy.

Competing interests: I was previously the Commissioner of the Queensland Ambulance service and chair of the Australian Ambulance Education Committee.

Provenance: Commissioned; externally peer reviewed..

(c) 2015 AMPCo Pty Ltd. Produced with Elsevier B.V. All rights reserved.

References are available online at www.mja.com.au. 
1 Lang ES, Spaite DW, Oliver ZJ, et al. A national model for developing, implementing, and evaluating evidence-based guidelines for prehospital care. Acad Emerg Med 2012; 19: 201209.

2 Smith E, Jennings P, McDonald S, et al. The Cochrane Library as a resource for evidence on out-of-hospital health care interventions. Ann Emerg Med 2007; 49: 344-350.

3 McCaul M, Lourens A, Kredo T. Pre-hospital versus in-hospital thrombolysis for ST-elevation myocardial infarction. Cochrane Database Syst Rev 2014; (9): CD010191.

4 Hurley KF, Magee K, Green R. Aminophylline for bradyasystolic cardiac arrest in adults. Cochrane Database Syst Rev 2013; (8): CD006781.

5 Austin M, Wood-Baker R. Oxygen therapy in the pre-hospital setting for acute exacerbations of chronic obstructive pulmonary disease. Cochrane Database Syst Rev 2006; (3): CD005534.

6 Snooks HA, Kingston MR, Anthony RE, Russell IT. New models of emergency prehospital care that avoid unnecessary conveyance to emergency department: translation of research evidence into practice? ScientificWorldJournal 2013; 2013: 182102. 